International Journal of Computer Science \& Engineering Survey (IJCSES) Vol.3, No.2, April 2012

\title{
Performance analysis of Coiflet-type wavelets for a fingerprint image compression by using wavelet and wavelet packet transform
}

\author{
Md. Rafiqul Islam ${ }^{1}$, Farhad Bulbul ${ }^{1}$ and Shewli Shamim Shanta ${ }^{2}$ \\ ${ }^{1}$ Mathematics Discipline, Khulna University, Khulna \\ mrislam_66@yahoo.com \\ ${ }^{2}$ Mathematics Dept. Rajshahi University, Rajshahi \\ farhad.math04@gmail.com
}

\begin{abstract}
Fingerprint analysis plays a crucial role in crucial legal matters such as investigation of crime and security system. Due to the large number and size of fingerprint images, data compression has to be applied to reduce the storage and communication bandwidth requirements of those images. To do this, there are many types of wavelet has been used for fingerprint image compression. In this paper we have used Coiflet-Type wavelets and our aim is to determine the most appropriate Coiflet-Type wavelet for better compression of a digitized fingerprint image and to achieve our goal Retain Energy (RE) and Number of Zeros (NZ) in percentage is determined for different Coiflet-Type wavelets at different threshold values at the fixed decomposition level 3 using wavelet and wavelet packet transform. We have used 8-bit grayscale left thumb digitized fingerprint image of size $480 \times 400$ as a test image.
\end{abstract}

\section{KEYWORDS}

Wavelets, wavelet packet decomposition, image compression, retain energy, percentage of zero

\section{INTRODUCTION}

Fingerprint verification is one of the most reliable personal identification methods and it plays a very important role in forensic and civilian applications. Between 1924 and today, the US Federal Bureau of Investigation (FBI) has collected about 30 million sets of fingerprints [2]. The archive consists mainly of inked impressions on paper cards. The big problem is the storage capacity of the data. From then they are thinking about digital storage. After the contribution of I. Daubechies in the field of orthonormal supported wavelet transformation, they started to think about electronic storage of the fingerprint. Facsimile scans of the impressions are distributed among law enforcement agencies, but the digitization quality is often low. Because a number of jurisdictions are experimenting with digital storage of the prints, incompatibilities between data formats have recently become a problem. This problem led to a demand in the criminal justice community for a digitization and compression standard.

For the above case the data storage problem is perspective. Fingerprint images are digitized at a resolution of 500 pixels per inch with 256 levels of gray-scale information per pixel. A single fingerprint is about 700,000 pixels and needs about 0.6 Mbytes to store. A pair of hands, then, requires about 6 Mbytes of storage. So digitizing the FBI's current archive would result in about 200 terabytes of data. At today's prices of about $\$ 900$ per Giga byte for hard-disk storage, the cost of storing these uncompressed images would be about 200 million dollars [1]. Obviously, data compression is important to bring these numbers down. In order for a system of this type of

DOI : $10.5121 /$ ijcses.2012.3209 
work in practice, it is necessary to be able to store the scanned data using as few bits as possible and it is necessary to have fast algorithms to extract the essential data from the finger being scanned. Wavelets fulfill both the conditions [3].

There is still need to develop faster, more strong and healthy algorithms for fingerprint images [5]. One of the main difficulties in developing compression algorithms for fingerprints is for preserving the minutiae i.e. ridges endings and bifurcations, which are subsequently used in identifications. To achieve high compression ratios while retaining these fine details, wavelet packet are used. Wavelet packet also save computational effort, transmission, and storage costs etc. Various image compression techniques are already exists like DCT, JPEG, and JPEG2000 [6] and Wavelet etc. all these techniques having their common aim to achieve high compression ratio. Among exiting compression techniques Wavelet gives better results for lossless as well as lossy image compression.

There are some wavelet families exists such as Symlets, Daubechies and Coiflets etc. and one may use different types of wavelet to compress fingerprint images or any other images. We would like to say that if we wish to compress fingerprint images or any other images by using a member of a wavelet family, then it would be better to use such a member who will give much better result among all members of that family. According to this, to find most useful member from Coiflet's wavelet family our paper have made an experiment on this family by compressing a fingerprint image. In this paper wavelet and wavelet packet transform have been used and most useful Coiflet-type wavelet has been chosen based on retain energy (RE) and number of zeros (NZ). In future if we want to use a member of Coiflet's wavelet family then it would be better to use that most useful member to obtain better compression.

\section{Related Works}

In the paper [13] the author's performed Wavelet packet transform on Fingerprint Image of size 374-by-388in two forms i.e. Image without noise and image with noise. Throughout the paper result of Haar, Daubechies (db1), and Symlet (sym2) transforms of Wavelet packet at three different threshold values are considered at level 3. For every threshold value of these transform for both types of images different compression result is achieved. This compression result is analyzed on the basis of retain energy and number of zeros present in the image after compression. They have achieved better compression result for Symlet wavelet packet transform rather than Haar and Daubechies for noisy and noiseless fingerprint images. But in our paper we have used the Coiflet-type Wavelets to compress 480-by- 400 fingerprint image. We also compare our result for wavelet and wavelet packet transform. Our experiment result is discussed in section 5 .

\section{Wavelets and Wavelet Packet for Compression}

Wavelet analysis has proved to be very important development in the search of more efficient methods of image compression. Like most Lossy image coders, wavelet based image coders typically comprise three major components. Wavelet filter bank decomposes an image into wavelet coefficients, which are then thresholded and quantized in Quantizer if necessary, and finally an entropy encoder encodes these quantized coefficients into out bit stream i.e. compressed image as shown in figure 1 


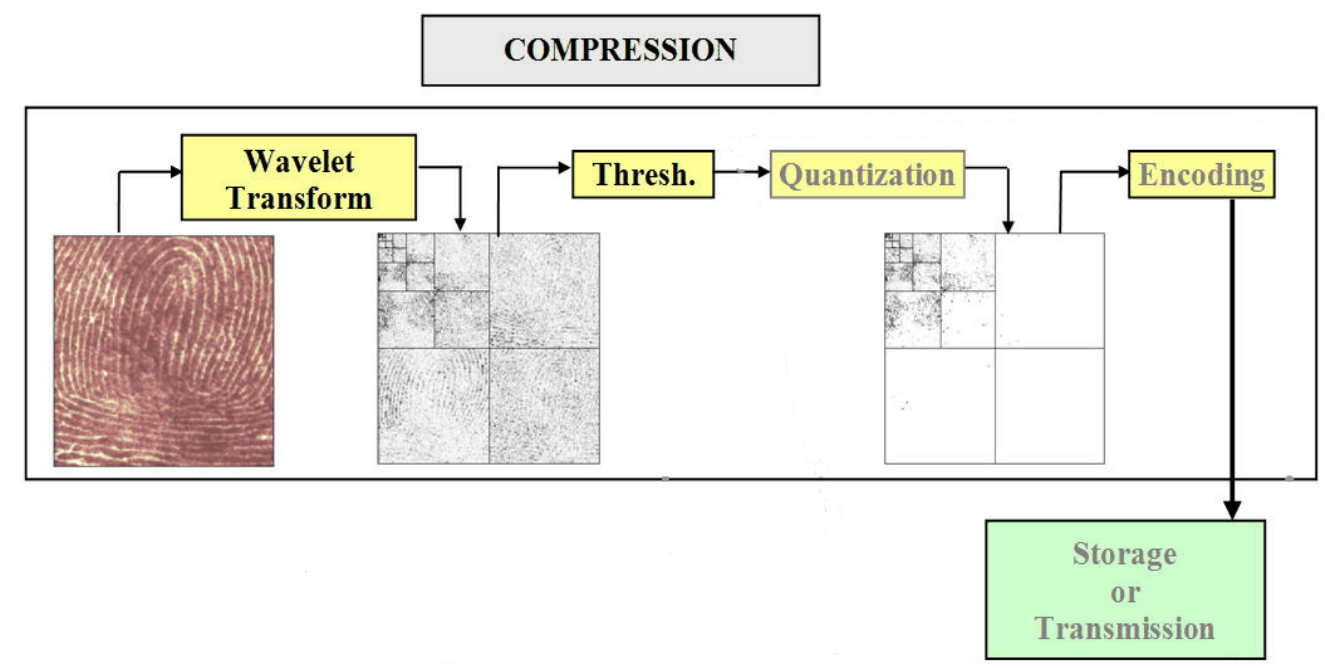

Figure 1. Shows the Lossy Image Compression System

\subsection{Wavelet Transform}

Wavelet transform is a pair of filters. The way we compute the wavelet transform by recursively averaging and differentiating coefficients is called the filter bank [4], where one is a low pass filter (lpf) and the other is a high pass filter (hpf). Each of the filters is down sampled by two and low frequencies signal of those two output signals can be further transformed. Similarly, this process can be repeated recursively several times, resulting in a tree structure called the decomposition tree. Wavelet transform can be used to analyze or decompose signals or images called decomposition [1][9][14][15]. The same components can be assembled back into the original signal without loss of information; this is called reconstruction or synthesis. The Wavelet decomposition structure has been shown in figure 2 .

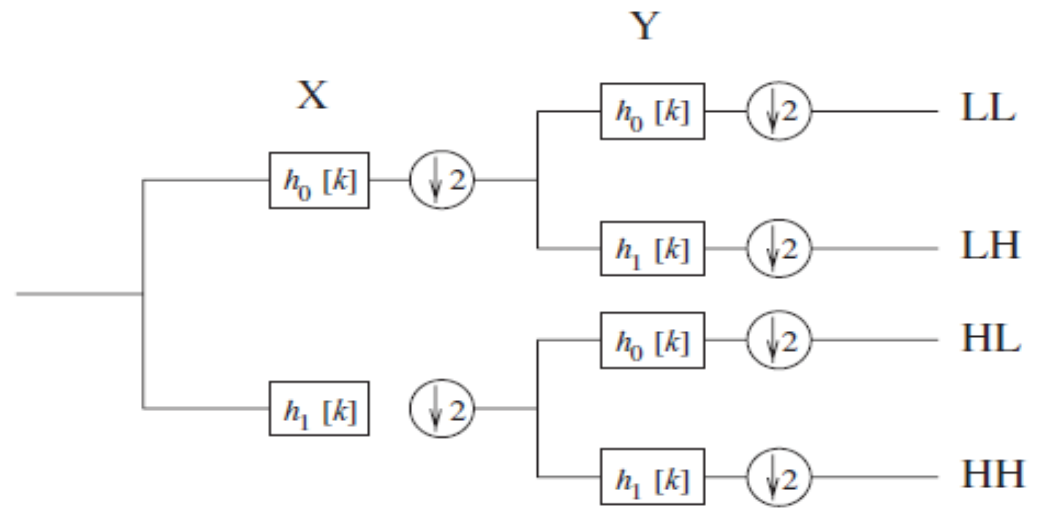

Figure 2. Analysis of 2D DWT shows one stage filter

The structure of Wavelet can be represented as a four channel perfect reconstruction of filter bank. Each filter is 2D with subscript indicating the type of filter (LPF or HPF) for separation of horizontal and vertical components. The resulting four-transform components consist of all possible combinations of high and low pass filtering in the two directions. By using these filters in one stage an image can be decomposed into four bands. There are three types of details of images for each resolution Diagonal (HH), Vertical (LH) and Horizontal (HL). The operations can be repeated on the low low (LL) i.e. on approximation band using the second identical filter 
bank [10]. The decomposition process can be iterated, with successive approximations being decomposed. However, in practice, more than one decomposition level is performed on the image data. Successive iterations are performed on the low pass coefficients (approximation) from the previous stage to further reduce the number of low pass coefficients. Since the low pass coefficients contain most of the original signal energy, this iteration process yields better energy compaction. The quality of compressed image depends on the number of decompositions. Compression of an image can be obtained by ignoring all coefficients less than the threshold value. If we use decomposition iteration, it will be more successful in resolving DWT coefficient because Human Visual System (HVS) is less sensitive to removal of smaller details. Decomposition iterations depend on the filter order. Higher order does not imply better image quality because of the length of the wavelet filter. This becomes a limiting factor for decomposition. Usually, three levels of decompositions are used in current wavelet based image compression $[7,12]$.

\subsection{Wavelet Packet Transform}

In addition to the above properties of wavelet transform, wavelet packets provide more flexible decomposition at any node of the decomposition by allowing decomposition at any node of the decomposition tree and also to obtain the best decomposition tree [5]. The benefit of the wavelet packets over the wavelet decomposition comes from the ability of the wavelet packets to better represent high frequency (this is how image may contains a noise) content, and high frequency oscillating signals in particular. This allows wavelet packet to perform significantly better than wavelets for compression of images with large amount texture and it is also point out the perceived image quality is significantly improved using wavelet packets instead of wavelets especially in the textured regions of the images [11].

Major difference between wavelet and wavelet packet is: The filter design associated with the wavelet analysis method involves iterating the low-pass and high -pass filtering and down sampling procedure only on the low-pass branch of the previous. While, wavelet packet (WP) presenting an extension of the octave band wavelet decomposition to full tree decomposition, i.e. the high pass output of each branch is also filtered and down sampled up to maximum number of decomposition this is one of the key difference between the wavelet and wavelet packet[16].

\section{Implementation}

We have implemented the above wavelet and wavelet packet algorithm in Coiflet's wavelet family for a fingerprint image compression. In our test we have used 8-bit gray scale left thumb digitized fingerprint image of size $480 \times 400$ in MATLAB program.

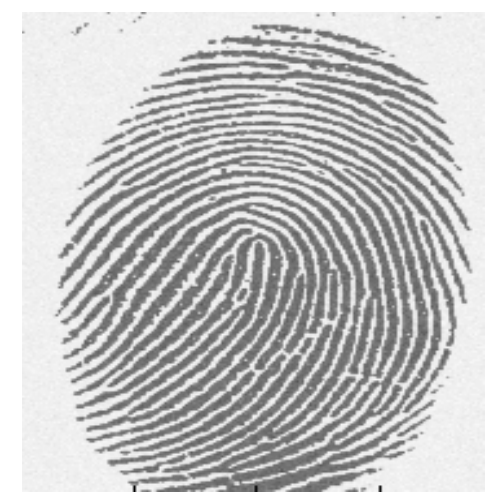

Figure 3. Left thumb digitized fingerprint image 
International Journal of Computer Science \& Engineering Survey (IJCSES) Vol.3, No.2, April 2012

For all Coiflet-type wavelets we have used global thresholding at values 235, 245 and 255 at the constant decomposition level 3. Results are observed in terms of percentage of zeros, percentage of energy retained. The results are presented in table 1 and table 2 for wavelet and wavelet packet transform respectively for having percentage of number of zeros (NZ) and percentage of energy retained (RE) as follows [8]:

$$
\begin{aligned}
& N Z=\frac{100 *(Z C D 100)}{\text { No of coefficients }} \\
& R E=\frac{100 *\left(V_{n}(C C D, 2)\right)^{2}}{\left(V_{n}(\text { Originalsignal })\right)^{2}}
\end{aligned}
$$

Where, $V_{n}$ is the vector norm, CCD is the coefficients of the current decomposition and ZCD is the Number of zeros of the current decomposition.

\section{Results and Discussion}

\begin{tabular}{|c|c|c|c|c|c|c|c|c|c|c|}
\hline & & & Type & of & avelet & ansf & $\mathrm{rm}$ at & d Leve & & \\
\hline \multirow{2}{*}{$\begin{array}{l}\text { Thresh } \\
\text { old } \\
\text { Value }\end{array}$} & \multicolumn{2}{|c|}{$\begin{array}{l}\text { Coiflet1 } \\
\text { (Coif1) }\end{array}$} & \multicolumn{2}{|c|}{$\begin{array}{l}\text { Coiflet2 } \\
\text { (Coif2) }\end{array}$} & \multicolumn{2}{|c|}{$\begin{array}{l}\text { Coiflet3 } \\
\text { (Coif3) }\end{array}$} & \multicolumn{2}{|c|}{$\begin{array}{l}\text { Coiflet4 } \\
(\text { Coif4) }\end{array}$} & \multicolumn{2}{|c|}{$\begin{array}{l}\text { Coiflet5 } \\
\text { (Coif5) }\end{array}$} \\
\hline & $\begin{array}{l}\mathrm{RE} \\
(\%)\end{array}$ & $\begin{array}{l}\mathrm{NZ} \\
(\%)\end{array}$ & $\begin{array}{l}\mathrm{RE} \\
(\%)\end{array}$ & $\begin{array}{l}\text { NZ } \\
(\%)\end{array}$ & $\begin{array}{l}\mathrm{RE} \\
(\%)\end{array}$ & $\begin{array}{l}\mathrm{NZ} \\
(\%)\end{array}$ & $\begin{array}{l}\mathrm{RE} \\
(\%)\end{array}$ & $\begin{array}{l}\mathrm{NZ} \\
(\%)\end{array}$ & $\begin{array}{l}\mathrm{RE} \\
(\%)\end{array}$ & $\begin{array}{l}\mathrm{NZ} \\
(\%)\end{array}$ \\
\hline 235 & 96.76 & $\begin{array}{l}97.5 \\
4\end{array}$ & 97.92 & $\begin{array}{l}97 . \\
33\end{array}$ & 98.37 & $\begin{array}{l}97 . \\
14\end{array}$ & $\begin{array}{l}98.6 \\
9\end{array}$ & 96.88 & $\begin{array}{l}98 . \\
88\end{array}$ & $\begin{array}{l}96.6 \\
8\end{array}$ \\
\hline 245 & 96.65 & $\begin{array}{l}97.5 \\
9\end{array}$ & 97.85 & $\begin{array}{l}97 . \\
37\end{array}$ & 98.33 & $\begin{array}{l}97 . \\
17\end{array}$ & $\begin{array}{l}98.6 \\
4\end{array}$ & 96.92 & $\begin{array}{l}98 . \\
84\end{array}$ & $\begin{array}{l}96.7 \\
1\end{array}$ \\
\hline 255 & 96.54 & $\begin{array}{l}97.6 \\
4\end{array}$ & 97.77 & $\begin{array}{l}97 . \\
41\end{array}$ & 98.27 & $\begin{array}{l}97 . \\
21\end{array}$ & $\begin{array}{l}98.6 \\
0\end{array}$ & 96.95 & $\begin{array}{l}98 . \\
80\end{array}$ & $\begin{array}{l}96.7 \\
4\end{array}$ \\
\hline
\end{tabular}

Table 1. RE and NZ for wavelet transform 
International Journal of Computer Science \& Engineering Survey (IJCSES) Vol.3, No.2, April 2012

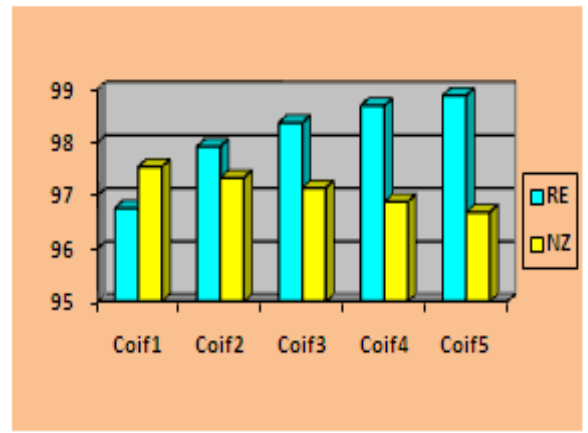

Threshold value 235

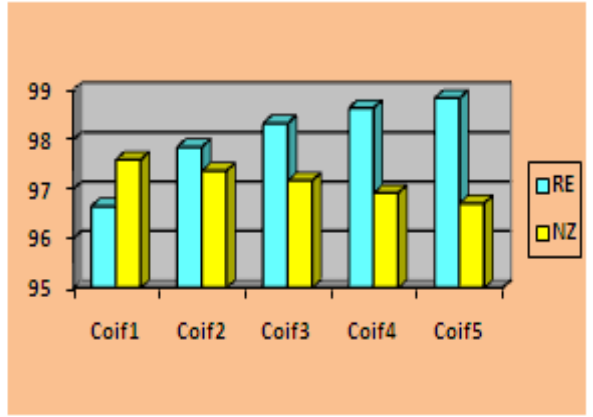

Threshold value 245

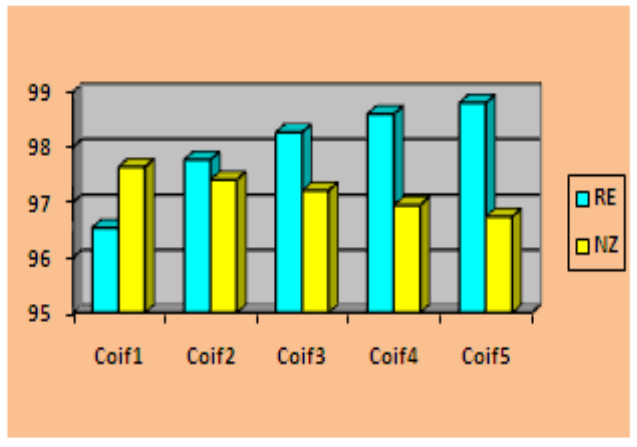

Threshold value 255

Figure 4. Graph for RE and NZ at different threshold value for Wavelet Transform

Table 2. RE and NZ for wavelet packet transform

\begin{tabular}{|c|c|c|c|c|c|c|c|c|c|c|}
\hline & & & Types & of Wav & let Tra & sform a & 3rd Lev & & & \\
\hline \multirow{2}{*}{$\begin{array}{l}\text { Thre } \\
\text { shol } \\
\text { d } \\
\text { Valu } \\
\text { e }\end{array}$} & \multicolumn{2}{|c|}{$\begin{array}{l}\text { Coiflet1 } \\
\text { (Coif1) }\end{array}$} & \multicolumn{2}{|c|}{$\begin{array}{l}\text { Coiflet2 } \\
\text { (Coif2) }\end{array}$} & \multicolumn{2}{|c|}{$\begin{array}{l}\text { Coiflet3 } \\
\text { (Coif3) }\end{array}$} & \multicolumn{2}{|c|}{$\begin{array}{l}\text { Coiflet4 } \\
\text { (Coif4) }\end{array}$} & \multicolumn{2}{|c|}{$\begin{array}{l}\text { Coiflet5 } \\
\text { (Coif5) }\end{array}$} \\
\hline & $\begin{array}{l}\mathrm{RE} \\
(\%)\end{array}$ & $\begin{array}{l}\mathrm{NZ} \\
(\%)\end{array}$ & $\begin{array}{l}\mathrm{RE} \\
(\%)\end{array}$ & $\begin{array}{l}\text { NZ } \\
(\%)\end{array}$ & $\begin{array}{l}\mathrm{RE} \\
(\%)\end{array}$ & $\begin{array}{l}\text { NZ } \\
(\%)\end{array}$ & $\begin{array}{l}\mathrm{RE} \\
(\%)\end{array}$ & $\begin{array}{l}\mathrm{NZ} \\
(\%)\end{array}$ & $\begin{array}{l}\mathrm{RE} \\
(\%)\end{array}$ & $\begin{array}{l}\mathrm{NZ} \\
(\%)\end{array}$ \\
\hline 235 & 97.03 & \begin{tabular}{|l|}
97.70 \\
\end{tabular} & 98.03 & \begin{tabular}{|l|}
97.81 \\
\end{tabular} & 98.40 & 97.90 & 98.66 & 97.97 & 98.81 & $\begin{array}{l}98.0 \\
2\end{array}$ \\
\hline 245 & 96.90 & 97.76 & 97.95 & 97.84 & 98.34 & 97.93 & 98.60 & 98 & 98.77 & $\begin{array}{l}98.0 \\
4\end{array}$ \\
\hline 255 & 96.77 & 97.81 & 97.87 & 97.88 & 98.26 & 97.97 & 98.55 & 98.03 & 98.72 & $\begin{array}{l}98.0 \\
7\end{array}$ \\
\hline
\end{tabular}




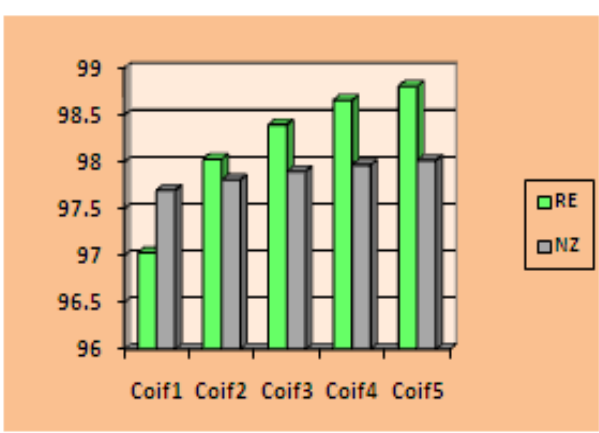

Threshold value 235

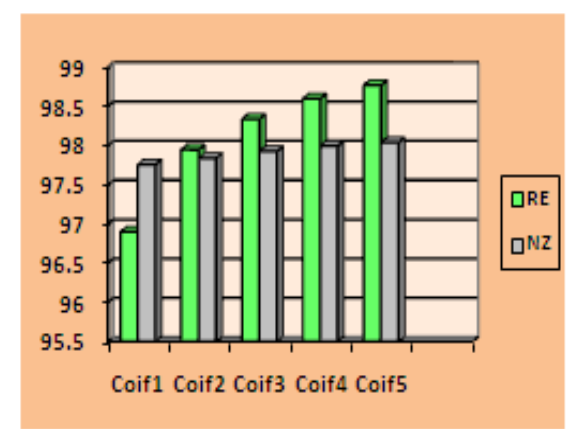

Threshold value 245

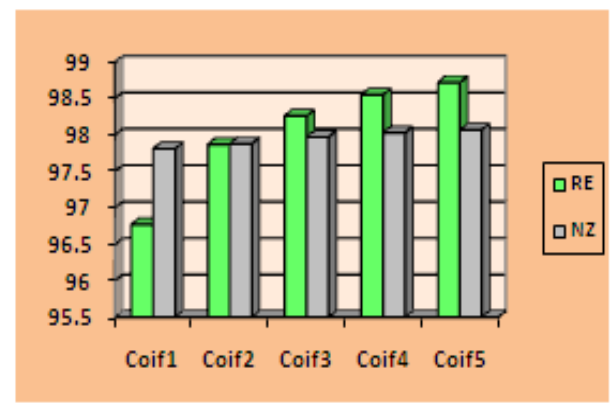

Threshold value 255

gure 5. Graph for RE and NZ at different threshold value for Wavelet packet Transform

In this section we have discussed the effect of order of Coiflet-type wavelet's on compression result through several graphs. For wavelet transform all figures show us all RE are increasing but NZ are decreasing with the increment of order of Coiflet-type wavelet for each threshold value, where the increasing rate of RE is comparatively more than the decreasing rate of NZ. For wavelet packet transform all figures show us RE and NZ both are increasing with the increasing of Coiflet-type wavelet's order for each threshold value and both increasing rate is comparatively good. From both transform we are observing that the higher order's Coiflet-type wavelet gives much better compression result i.e. more RE and NZ than his lower order's Coiflet-type wavelet's and hence for both transform Coif5 provides maximum RE and NZ in all Coiflet-type wavelet's. Hence we would like to say that RE and NZ are increasing by increasing order of Coiflets wavelet.

\section{CONCLUSIONS}

In this paper we have analyzed every Coiflet-type wavelet of Coiflet's wavelet family by compressing a fingerprint image by using wavelet and wavelet packet transform at three different threshold values at decomposition level three. The experiment result is that the Coiflet5 is much better than other Coiflet-type wavelets for fingerprint image compression for wavelet transform. Another experiment result is that the Coiflet5is much better than other Coiflet-type wavelets for the same fingerprint image for wavelet packet transform. In both cases we use the percentage of Retain Energy (RE) and percentage of Number of Zeros (NZ). In the case of wavelet transform percentage of Retain Energy (RE) is improved and percentage of Number of Zeros (NZ) is decreased. But in the case of wavelet packet transform the percentage 
International Journal of Computer Science \& Engineering Survey (IJCSES) Vol.3, No.2, April 2012

of Retain Energy (RE) and percentage of Number of Zeros (NZ) both are improved. Hence wavelet packets transform gives much better result than wavelet transform.

\section{REFERENCES}

[1] Ali Reza, (1999), "From Fourier Transform to Wavelet Transform basic concepts", spire Lab, UWM oct-27.

[2] Bradley, J., C. Brislawn and T. Hopper, (1993), "The FBI Wavelet/Scalar Quantization Standard for Gray-scale Fingerprint Image Compression”, Tech. Report LA-UR-93-1659, Los Alamos Nat'1 Lab, Los Alamos, N.M.

[3] O. Christensen, and K.L. Christensen, (2004), “Approximation Theory”, From Taylor polynomials to wavelets, Birkhäuser, Boston.

[4] Geeta S. Rao, (2004), "Wavelet Analysis and Applications”, New Age International Publishers.

[5] Karen Lees, (2002), “Image Compression Using Wavelets”, Report of MS.

[6] Milan Sonka Roger Boyle, (1996), "Image Processing Analysis \& Machine Vision”, Reprint By international Thomson Computer press.

[7] Michael B. Martin, (1999), "Application of Wavelets to image Compression”, M.S. Thesis, Blacksburg Virigina.

[8]. Misiti, M. Misiti, Y. Oppenheim, G. Poggi, and J-M, (2000), “Wavelet Toolbox User.s Guide”, Version 2.1.The Mathworks, Inc..

[9] P.D.Deshmuk, R.R. Manza and K.V.Kale, (2004), "Decomposition for Fingerprint images", Proceeding National Conference CCS-04 Aurangabad Conducted by IETE Chapter and Dept. of Comp. Science Dr. BAMU Aurangabad, India.

[10] Sonja Grigic, Mislav Grigic and Branko Zovko-Cihlar, (2001), “Performance Analysis of Image Compression using Wavelets ", IEEE Transactions on Industrial electronics, Vol.48. N0.3, PP.682-695.

[11] S. S. Gornale, R. R. Manza, Vikas Humbe and K.V.Kale, (2004), "Performance Analysis of Wavelets to Multiwavelets for noisy image Compression", Proceeding Of National Conference on Geometry, Analysis, Fluid Mechanics and Computer Applications, Organized by the Dept. of Studies in Mathematics and Computer Science, Kuvempu University, Karnataka, India.

[12] Sonja Grigic, Mislav Grigic and Bronka zovko, (2000) "Optimal Decomposition for Wavelet Image Compression ", First International Workshop on Image and Signal Processing And Analysis, June 14-15, Pula, Coatia .

[13] Shivanand S. Gornale, Vikas T. Humbe, Ramesh R Manza and K. V. Kale,(2004), "Fingerprint Image Compression using Retain Energy (RE) and Number of Zeros (NZ) through Wavelet Packet (WP)", International Journal of Computer Science and Security, Volume 1: Issue (2).

[14] T.K.Sarkar,C.Su, R Adve, M. Salazar-Palma L Carcia-Castilla and Rafeal R. Boix, (1998), “ A Tutorial on wavelets from an Electrical Engg. Perspective Part-1 Discrete Wavelet Techniques", IEEE Antenna and Propagation Magazine, Vol.40. No.5.

[15] Wavelet Toolbox users Guide, www.mathworks.com

[16] Zixing, Xiong,Kannan Ramchandran and Michel T Orchad(2001) "Wavelet Packet Image Coding Space Frequency Quantization”,IEEE Tran. on Image Processing, Vol 7, No.6. 


\section{AUTHORS BIOGRAPHY}

Md. Rafiqul Isalm is currently working as a Professor in the Mathematics discipline at Khulna University, Bangladesh. He received his M.Sc degree in Mathematics from King Fahd University of Petroleum and Minerals, Saudi Arabia. He also received his B.Sc. (Hon's) degree in Mathematics and another M.Sc degree in Applied Mathematics from Rajshahi University, Bangladesh. He is pursuing his $\mathrm{PhD}$ from Rajshahi University, Bangladesh. He has published over 20 research articles in International and national journals. His research areas of interest include Signal and Image processing, Wavelets, Fourier series.

Md. Farhad Bulbul has been completed M.Sc in applied Mathematics in the Mathematics discipline at Khulna University, Bangladesh. He received his B.Sc. (Hon's) degree in Mathematics with distinction from Khulna University, Bangladesh. He has some accepted and submitted paper for publication in International journals. His research areas of interest include Image processing, Wavelets, Fourier series.
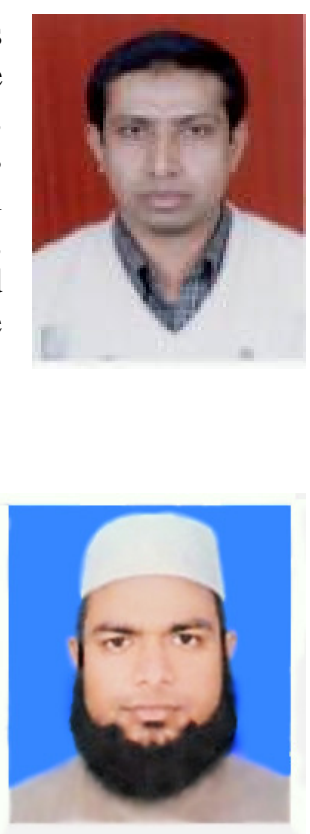

Shewli Shamim Shanta is currently working working as a Professor in the Department of Mathematics at Rajshahi University, Bangladesh. She received her B.Sc. (Hon's) degree in Mathematics and another M.Sc degree in Applied Mathematics from Rajshahi University, Bangladesh. She did her PhD from Japan. She has published 12 research articles in International and national journals. Her research areas of interest include Signal and Image processing, Wavelets, Fourier series. 